\title{
Prevalence of Congenital Tooth Deficiency: Retrospective Cross-Sectional Study
}

\author{
Can Özükoç \\ Department of Pediatric Dentistry, Istanbul Medipol University, Turkey
}

\begin{abstract}
This study aims to determine the prevalence of congenitally missing permanent teeth in children between the ages of $5-14$ and resident in İstanbul.

The clinical and radiological records of patients aged 7-14 years were evaluated retrospectively by examining the presence of tooth deficiency, localization and distribution on gender. The data obtained were evaluated statistically by the Fisherexact Chi-Square test.

It was determined that 1604 of a total of 19218 children whose records were examined had congenitally missing permanent teeth, $51.37 \%$ of these missing teeth were hypodontia and $0.18 \%$ were oligodontia. Congenital tooth deficiency was found more in female $(51.99 \%)$ than male $(48.01 \%)$. The most common congenitally missing permanent teeth were maxillary second premolar $(40.19 \%)$, maxillary lateral incisor $(25.20 \%)$, and maxillary 2 nd premolar teeth $(20.06 \%)$ respectively and the least common were maxillary and mandibular 2nd molar teeth $(0.03 \%)$. Mandibular 2nd premolar missing teeth were more frequently incident in females (54.48\%) compared to males and there was a statistically significant difference $(\mathrm{p}<0.05)$. Similarly, maxillary lateral incisor missing tooth was found to be more frequent in females $(54.03 \%)$ and there was a statistically significant difference $(\mathrm{p}<0.05)$.

Detailed clinical and radiological examinations play a major role in the diagnosis and treatment of congenitally missing teeth and are of the essence in terms of early diagnosis of congenitally missing teeth and treatment planning.
\end{abstract}

Keywords: Congenitally missing teeth, Hypodontia, Oligodontia, Pediatric Dentistry, Prevalence

\section{Introduction}

The condition of having one or more missing teeth is defined as the most common developmental anomaly in humans. Many terms are used to describe these numerical anomalies. The term congenitally missing teeth includes terms causing confusion in terminology such as hypodontia, oligodontia, dental agenesis, absence of teeth, etc., and it is generally accepted in the dental literature. Although the aetiology of congenitally missing teeth is not known exactly, it is reported that both genetic and environmental factors might be effective $(1,2)$. Congenitally missing teeth might cause functional and aesthetic problems in people and might lower selfconfidence (3). Early diagnosis of congenitally missing teeth is of critical importance in preventing future complications or reducing the severity. Although there are many studies (4-14) on the distribution and prevalence of congenitally missing teeth that cause periodontal damage, loss of aesthetics and function as well as imperfections in row of teeth, data on children in the Turkish population is quite limited $(15,16)$.

This study aims to evaluate the prevalence and missing teeth of patients who applied to the clinic and were diagnosed with congenitally missing teeth, according to localization of missing teeth, and to examine them according to age and gender.

\section{Materials and Methods}

Study Design: The design of this retrospective cross-sectional study was prepared in line with the recommendations of the STROBE (Strengthening the Reporting of Observational studies in Epidemiology) initiative. The study was commenced upon the permission of the Istanbul Medipol University Ethics Committee numbered 202 on 18.02.2021. Records of 19218 patients between the ages of 7-14 who applied for examination were examined. Radiographs and patient files of children by examining the anamnesis forms taken from the patients without a history of extraction of permanent teeth or 


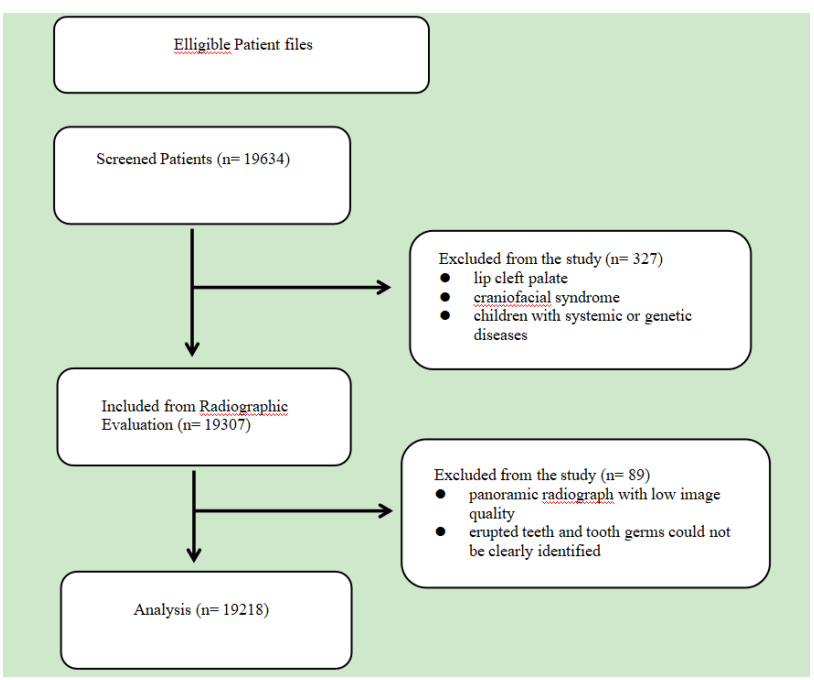

Fig. 1. STROBE flowchart

impacted permanent teeth were examined. Children with lip cleft palate and craniofacial syndrome, children with systemic or genetic diseases and those, who underwent extraction of permanent teeth, and the patients, who have low panoramic radiograph with low image quality, where erupted teeth and tooth germs could not be clearly identified, were not included in the study.

All selected panoramic films were examined by the same operator in a dark room using a digital viewer and if mineralization of crown could not be determined in radiography (except for third molars), the teeth were considered congenitally missing. STROBE flowchart of the study is shown in figure 1.

Statistical Analysis: Statistical evaluation was performed using SPSS v23 (SPSS Inc., Chicago, IL, USA) software package program. The cases were investigated in terms of gender and localization of missing teeth. The data obtained were evaluated statistically by the Fisher-exact Chi-Square test. The $\mathrm{p}<0.05$ values were considered to be statistically significant in all tests.

\section{Results}

After radiographic evaluation and examination of patient records, 1604 (8.35\%) pf 19218 children were found to have congenitally missing teeth. The total number of missing teeth was found to be 2607. Missing teeth were found to be more frequent in females $(\% 51.99)$, but there was no statistically significant difference $(\mathrm{p}>0.05)$. Similarly, one missing tooth was found to be more frequent in females $(51.94 \%)$, but there was no statistically significant difference $(p>0.05)$. It was seen that the prevalence of oligodontia was higher in males $(75 \%)$ and the difference was statistically significant. $(\mathrm{p}<0.05)$ The distribution of congenitally missing teeth is presented in Table 1 .

When the distribution of missing teeth according to types of teeth, was examined, except for the third permanent molars, it was found that the most commonly missing teeth were mandibular 2nd premolars $(40.19 \%)$, maxillary lateral incisors $(25.20 \%)$, and maxillary 2 nd premolars $(20.06 \%)$, respectively and the least commonly missing teeth were maxillary and mandibular 2nd molar teeth $(0.03 \%)$. When the relationship between gender and types of missing teeth was examined, it was found that missing 2 nd premolar teeth were more frequent in females $(54.48 \%)$ compared to males and there was a statistically significant difference $(p<0.05)$. Similarly, missing maxillary lateral incisor teeth were more frequent in females $(54.03 \%)$ and there was a statistically significant difference $(\mathrm{p}<0.05)$. Missing maxillary and mandibular first premolar teeth and missing maxillary central incisor teeth were more frequent in males and there was a statistically significant difference $(p<0.05)$. The distribution of missing teeth by types of teeth and gender is shown in Table 2 .

When the number of missing teeth between jaws was evaluated, it was found that there were more missing teeth in the maxillary jaw (\%51.8) compared to the mandibular jaw (\%48.2), but this difference was not statistically significant $(p>0.05)$. When the number of missing teeth in the right and left sides of jaws was evaluated, missing teeth in the left side $(\% 50.5)$ were found to be more compared to the right side (\%49.5), however, the difference was not statistically significant $(p>0.05)$.

\section{Discussion}

Congenitally missing teeth is one of the most common dental anomalies in humans and many pieces of research on the prevalence of congenitally missing teeth have been conducted so far. Although there are many studies in the literature to determine the prevalence of congenitally missing teeth, it is seen that the studies conducted in the Turkish population are limited $(15,19)$. On the other hand, it is observed that the studies conducted are insufficient to examine the pediatric population, they are generally studies on orthodontic patients and only the data obtained from panoramic radiographs are evaluated. Therefore this study aimed to evaluate missing teeth and the prevalence of congenitally missing teeth in the Turkish population according 
Table 1. Distribution of Congenitally Missing Teeth By Gender

\begin{tabular}{lcccc}
\hline $\begin{array}{l}\text { Number of } \\
\text { teeth }\end{array}$ & $\begin{array}{c}\text { Female } \\
\mathrm{n}(\%)\end{array}$ & $\begin{array}{c}\text { Male } \\
\mathrm{n}(\%)\end{array}$ & Total & $\mathrm{p}$ Value \\
\hline 1 & $428(51.94 \%)$ & $396(48.06 \%)$ & $824(51.37 \%)$ & 0.722 \\
2 & $330(53.48 \%)$ & $307(46.52 \%)$ & $617(38.46 \%)$ & 0.621 \\
3 & $63(52.50 \%)$ & $46(47.50 \%)$ & $120(7.48 \%)$ & 0.578 \\
4 & $20(55.55 \%)$ & $16(44.45 \%)$ & $36(2.24 \%)$ & 0.608 \\
5 & $2(50 \%)$ & $2(50 \%)$ & $4(0.24 \%)$ & 0.922 \\
$\geq 6$ & $1(25 \%)$ & $* 3(75 \%)$ & $3(0.18 \%)$ & $* 0.009$ \\
\hline
\end{tabular}

*Statistically difference $(\mathrm{p}<0.05)$

Table 2. The Distribution of Missing Teeth By Types of Teeth and Gender

\begin{tabular}{lcccc}
\hline \multirow{2}{*}{ Missing Tooth } & \multicolumn{2}{c}{ Gender } & Total & $\mathrm{p}$ \\
\cline { 2 - 3 } & Female $\mathrm{n}(\%)$ & Male $\mathrm{n}(\%)$ & $\mathrm{n}(\%)$ & Value \\
\hline Mandibular second premolar & $571(54.48 \%)$ & $477(45.52 \%)$ & $1048(40.19 \%)$ & $* 0.042$ \\
Maxillary lateral incisor & $355(54.03 \%)$ & $302(45.97 \%)$ & $657(25.20 \%)$ & $* 0.048$ \\
Maxillary second premolar & $265(50.66 \%)$ & $258(49.34 \%)$ & $523(20.06 \%)$ & 0.884 \\
Maxillary canine & $52(53.06 \%)$ & $46(46.94 \%)$ & $98(3.75 \%)$ & 0.590 \\
Mandibular lateral incisor & $41(48.23 \%)$ & $44(51.77 \%)$ & $85(3.26 \%)$ & 0.725 \\
Maxillary first premolar & $30(44.11 \%)$ & $38(55.89 \%)$ & $68(2.60 \%)$ & $* 0.038$ \\
Mandibular first premolar & $30(45.45 \%)$ & $36(54.55 \%)$ & $66(2.53 \%)$ & $* 0.040$ \\
Mandibular central & $11(52.38 \%)$ & $10(47.62 \%)$ & $21(0.80 \%)$ & 0.625 \\
Maxillary central & $9(42.85 \%)$ & $12(57.15 \%)$ & $21(0.80 \%)$ & $* 0.026$ \\
Mandibular canine & $4(44.44 \%)$ & $5(55.56 \%)$ & $9(0.34 \%)$ & 0.687 \\
Mandibular first molar & $2(40 \%)$ & $3(60 \%)$ & $5(0.19 \%)$ & 0.620 \\
Maxillary first molar & $2(50 \%)$ & $2(50 \%)$ & $4(0.15 \%)$ & 0.925 \\
Mandibulary second molar & $1(100 \%)$ & $0(0 \%)$ & $1(0.03 \%)$ & 0.956 \\
Maxillary second molar & $0(0 \%)$ & $1(100 \%)$ & $1(0.03 \%)$ & 0.964 \\
\hline
\end{tabular}

to their localization and to examine them according to age and gender.

When studies conducted in the literature without distinguishing between children and adults were examined (12,18-21), the prevalence of congenitally missing teeth was reported to be $1.2 \%$ to $36.5 \%$. When the studies on the prevalence of congenitally missing teeth conducted in the pediatric population are examined $(22,23)$, prevalence values are reported to range between $0,8 \%$ and $12.6 \%$. When the reason for these difference prevalence values is examined, it is thought that age ranges and differences in examination methods in the studies might cause this difference $(12,21,24,25)$. Besides, it is understood that in many studies regional and racial differences considerably affect the prevalence results and the number distribution of teeth (25). Similar to the studies of Behr et al (22) and Nik-Hussein (23), the prevalence of missing teeth was found to be $8.35 \%$ in this study, as well.
It is stated that the calcifications of permanent tooth germs start at birth and continue until the age of 6 (26). In the literature, it is stated that there may be a delay in calcification of the mandibular second premolars, and it would be erroneous to record this tooth as a missing tooth in children under 7 years of age $(27,28)$. The study conducted by Amini et al (27) supports this thought and when samples that are especially children at the age of 5 to 7 were compared with themselves 2 years later, they found that there was a decrease in the prevalence of missing teeth due to late mineralization of second premolar teeth. However, some researchers rejected this dissertation and reported in their studies that only 1 out of 776 7-year-old children had late mineralization (28). Similarly, it is possible to make erroneous evaluations due to extraction of teeth after the age of 14 for various reasons (decayed took, dental trauma, etc.) and spontaneous closure of lost permanent teeth or

East J Med Volume:27, Number:1, January-March/2022 
the patient not remembering the extraction of permanent teeth in the past. Therefore, it is more appropriate to determine the age range as $7-14$ in this study, but the difference that may occur due to late mineralization constitutes the limitation of this study.

It is not known exactly whether gender has an effect on congenitally missing teeth. Some opinions indicating the fact that females have more congenitally missing teeth might affect the formation of tooth germs due to smaller jaw structures were reported $(29,30)$. Similarly, in this study, females were found to have more congenitally missing teeth and there was no statistically significant difference except for missing mandibular 2nd premolar teeth and missing maxillary lateral incisor, whereas the prevalence of oligodontia (6 or more missing teeth) was found to be more frequent in male children $(75 \%)$ similar to previous studies $(12,17,19-21,31)$ and there was a statistically significant difference $(\mathrm{p}<0.05)$.

When the distribution of missing teeth according to types of teeth, was examined, it was found that the most commonly missing teeth were mandibular second premolars (40.19\%), maxillary lateral incisors $(25.20 \%)$, and maxillary second premolars $(20.06 \%)$, respectively. Second permanent molar teeth $(0.03 \%)$ were found to be the least common missing teeth and the results were found to be consistent with previous studies $(12,15,16,21)$ on children.

When the localization of missing teeth is examined, missing teeth were found to be more frequent in the maxillary jaw $(51.8 \%)$ and on the left side $(50.5 \%)$ and the results were not statistically significant but consistent with previous studies $(15,16,21)$.

In conclusion, it is seen that no consensus has been reached in general in terms of the most commonly missing teeth or prevalence values or distribution by gender. Evaluation of different gene pools and a small number of samples creates difficulties in comparing studies. Therefore, examining more patients from different regions will provide more precise and detailed data in creating data regarding children in our country.

Conflict of interests: There is no conflict of interests.

\section{References}

1. Goldenberg $M$, Das P, Messersmith M. Clinical, Radiographic and Genetic Evaluation of Novel Form of Autosomal-Dominant Oligodontia. J Dent Res 2000; 79: 1469-1475.

2. Oeschger ES, Kanavakis G, Halazonetis DJ. Number of teeth is associated with facial size in humans. Sci Rep 2020; 15: 59-64.

3. Gracco ALT, Zanatta S, Forin Valvecchi F. Prevalence of dental agenesis in a sample of Italian orthodontic patients: an epidemiological study. Progress in orthodontics 2017; 18: 33.

4. Mckibben DR, Brearley LJ. Radiographic determination of the prevalence of selected dental anomalies in children. J Dent Child 1971; 38: 390-398.

5. Locht S. Panoramic radiographic examination of 704 Danish children aged 9-10 years. Community Dent Oral Epidemiol 1980; 8: 375-380.

6. Cunha AS, dos Santos LV, Marañón-Vásquez GA. Genetic variants in tooth agenesis-related genes might be also involved in tooth size variations. Clin Oral Invest 2021; 25: $1307-$ 1318.

7. Pilo R, Kaffe I, Amir E, Sarnat H. Diagnosis of develepmental dental anomalies using panoromic radiographs. J Dent Child 1987; 54: 267-272.

8. Muller TP, Hill IN, Petersen AC, Blayney JR. A survey of congenitally missing permanent teeth. J Am Dent Assoc 1970; 81: 101-107.

9. Endo T, Ozoe R, Kubota M, Akiyama M, Shimooka S. A survey of hypodontia in Japanese orthodontic patients. Am J Orthod Dentofacial Orthop 2006; 129: 29-35.

10. Silva Meza R. Radiographic assessment of congenitally missing teeth in orthodontic patients. Int J Paed Dent 2003; 13: 112-126.

11. Davis PJ. Hypodontia and hyperdontia of permanent teeth in Hong Kong schoolchildren. Community Dent Oral Epidemiol 1987; 15: 218-220.

12. Lynham A. Panoromic radiographic survey of hypodontia in Australian Defence Force recruits. Aus Dent J 1989; 35: 19-22.

13. Maklin M, Dummett CO, Weinberg R. A study of oligodontia in a sample of New Orleans children. J Dent Child 1979; 46: 478-482.

14. Mahaney MC, Fujiwara TM, Morgan K. Dental agenesis in the Dariusleut Hutterite Brethren: comparisons to selected Caucasoid population surveys. Am J Phys Anthropol 1990; 82: 165177.

15. Uzamış M, Taner TU, Kansu Ö, Alpar R. Evaluation of dental anomalies in 6-13 year old turkish children: a panoramic survey. J Marmara Un Dent Fac 2001; 4: 254-259.

16. Sumer P, Akça T, Köprülü H. Çocuklarda görülen dental anomaliler: Panoromik

East J Med Volume:27, Number:1, January-March/2022 
radyografik değerlendirme. Ondokuz Mayıs Univ Diş Hekim Fak Derg 2004; 5: 81-84.

17. Bilge NH, Yeşiltepe S, Törenek Ağırman K, Çağlayan F, Bilge OM. Investigation of prevalence of dental anomalies by using digital panoramic radiographs. Folia morphologica 2018; 77: 323-328.

18. Uzuner D, Celik MM, Toy E, Turkdonmez CO. Assessment of hypodontia in the Turkish patients referring to the orthodontic clinic: A retrospective study. Eur J Dent. 2013; 7: 9-14.

19. Topkara A, Sari Z. Prevalence and distribution of hypodontia in a Turkish orthodontic patient population: results from a large academic cohort. European Journal of Paediatric Dentistry 2011; 12: 123-127.

20. Nordgarden H, Jensen JL, Storhaug K. Reported Prevalence of Congenitally Missing Teeth In Two Norwegian Counties. Community Dent Health 2002; 19: 258-261.

21. Traikiniene G, Ryliskyte M, Kiausatie A. Prevalence of Teeth Number Anomalies In Orthodontics Patients. Stomatologia 2013; 158: 45-53.

22. Behr M, Proff P, Leitzmann M, Pretzel M, Handel G, Schmalz G. Survey of congenitally missing teeth in orthodontic patients in Eastern Bavaria. European journal of orthodontics. 2011; 33: 32-36.

23. Nik-Hussein NN. Hypodontia in the permanent dentition: a study of its prevalence in Malaysian children. Australian Orthodontic Journal 1989; 11: 93-95.
24. Aasheim B, Ögaard B. Hypodontia In 9-yearold Norwegians Related to Need of Orthodontic Treatment. Scand J Dent Res 1993; 101: 257-60.

25. Sheikhi M, Sadeghi MA, Ghorbanizadeh S. Prevalance of Congenitally Missing Permanent Teeth. Dent Res J 2012; 9: 105-11.

26. Zhu JF, Marcushamer M, King DL, Henry RJ. Supernumerary and congenitally absent teeth: a literature review. The journal of clinical pediatric dentistry 1996; 20: 87-95.

27. Amini F, Rakhshan V, Babaei P. Prevalence and pattern of hypodontia in the permanent dentition of 3374 Iranian orthodontic patients. Dental research journal 2012; 9: 245-250.

28. Polder BJ, Van't Hof MA, Van der Linden FP, Kuijpers-Jagtman AM. A meta-analysis of the prevalence of dental agenesis of permanent teeth. Community dentistry and oral epidemiology 2004; 32: 217-226.

29. Rakhshan V. Congenitally missing teeth (hypodontia): A review of the literature concerning the etiology, prevalence, risk factors, patterns and treatment. Dental research journal 2015; 12: 1-13.

30. Varela M, Arrieta P, Ventureira C. Nonsyndromic concomitant hypodontia and supernumerary teeth in an orthodontic population. European journal of orthodontics 2009; 31: 632-637.

31. Zengin AZ, Çelenk P, Sumer P, Canger EM. Distribution of Missing Teeth According To Sex and Localization In Oligodontia. Atatürk Üniversitesi Diş Hekimliği Fakültesi Dergisi 2009; 19: 137-144. 